2010-11-02

Lexical stress and phonetic processing in word learning in 20- to 24-month-old English-learning children

Floccia, Caroline

http://hdl.handle.net/10026.1/9955

10.1111/j.1467-7687.2010.01006.x

DEVELOPMENTAL SCIENCE

Wiley

All content in PEARL is protected by copyright law. Author manuscripts are made available in accordance with publisher policies. Please cite only the published version using the details provided on the item record or document. In the absence of an open licence (e.g. Creative Commons), permissions for further reuse of content should be sought from the publisher or author. 


\title{
PAPER
}

\section{Lexical stress and phonetic processing in word learning in 20- to 24-month-old English-learning children}

\section{Caroline Floccia, ${ }_{1}^{1}$ Thierry Nazzi, ${ }^{2,3}$ Keith Austin, ${ }^{4}$ Frédérique Arreckx ${ }^{5}$ and Jeremy Goslin ${ }^{1}$}

1. School of Psychology, University of Plymouth, UK

2. Université Paris Descartes, France

3. Laboratoire Psychologie de la Perception, CNRS, Paris, France

4. School of Psychological Science, University of Manchester, UK

5. School of Early Years and Primary Education Studies, University of Plymouth, UK

\begin{abstract}
To investigate the interaction between segmental and supra-segmental stress-related information in early word learning, two experiments were conducted with 20- to 24-month-old English-learning children. In an adaptation of the object categorization study designed by Nazzi and Gopnik (2001), children were presented with pairs of novel objects whose labels differed by their initial consonant (Experiment 1) or their medial consonant (Experiment 2). Words were produced with a stress initial (trochaic) or a stress final (iambic) pattern. In both experiments successful word learning was established when the tobe-remembered contrast was embedded in a stressed syllable, but not when embedded in unstressed syllables. This was independent of the overall word pattern, trochaic or iambic, or the location of the phonemic contrast, word-initial or -medial. Results are discussed in light of the use of phonetic information in early lexical acquisition, highlighting the role of lexical stress and ambisyllabicity in early word processing.
\end{abstract}

\section{Introduction}

Decades of research have established young infants' superiority over adults when discriminating phonetic contrasts (Eilers, Gavin \& Wilson, 1979; Lasky, SyrdalLasky \& Klein, 1975; Streeter, 1976; Trehub, 1976), with infants exhibiting the ability to discriminate various phonetic contrasts from their first year of life (e.g. Eimas, Siqueland, Juscyzk \& Vigorito, 1971; Trehub, 1976). However, this advantage does not transfer to the early perceptual processing of words, especially when infants are required to process both form and meaning, with 14-month-old infants failing to learn minimal pairs of non-words differing by a single consonant (Stager \& Werker, 1997; but see Rost \& McMurray, 2009; Yoshida, Fennell, Swingley \& Werker, 2009).

This sharp contrast between phonemic discrimination and the processing of words has generated many studies, as it can offer important insight into the specificity of lexical representations in early word learning or recognition. The emerging picture reveals the immaturity of the phonetic processing of early lexical representations, highlighted in tasks involving the detection of consonant or vowel mispronunciation for familiar or newly learnt words (Bailey \& Plunkett, 2002; Fennell \& Werker, 2003; Hallé \& de Boysson-Bardies, 1996; Mani \& Plunkett, 2007, 2008; Nazzi, 2005; Nazzi, Floccia, Moquet \& Butler, 2009; Swingley, 2003; Swingley \& Aslin, 2000; Vihman, Nakai, DePaolis \& Hallé, 2004). Two sets of explanations have so far been offered to account for this limited level of phonetic processing of early lexical representations. Proponents of the discontinuity hypothesis have argued for the existence of holistic representations at the onset of the second year of life (e.g. Charles-Luce \& Luce, 1990; Hallé \& de Boysson-Bardies, 1996; Metsala \& Walley, 1998), followed by a reorganization of the lexicon as vocabulary increases in the second year of life (Walley, 1993). According to the continuity hypothesis, detailed phonetic lexical representations are maintained throughout infancy and childhood, but access to these representations is impinged on at around 1 year of age because of the computational load of linking sounds to meaning (Stager \& Werker, 1997; see Saffran \& Estes, 2006, for a review).

However, most research has focused on aspects of phonetic specificity and lexical representations, while very little attention has been paid to interactions between supra-segmental and segmental information (but see 
Vihman et al., 2004; Johnson, 2005). Prosody plays a fundamental role in early language development, guiding early acquisitions such as maternal voice recognition (see Floccia, Nazzi \& Bertoncini, 2000, for a review) and language discrimination abilities (Nazzi, Jusczyk \& Johnson, 2000), but also providing some cues for word segmentation in continuous speech (Jusczyk, Houston \& Newsome, 1999; Nazzi, Iakimova, Bertoncini, Frédonie \& Alcantara, 2006) or for the acquisition of syntactic parameters (e.g. Christophe, Nespor, Guasti \& Van Ooijen, 2003). Therefore it is perhaps unsurprising that during the first year of life there is abundant evidence for a prosodic bias in early speech processing, before the integration of segmental information (see Höhle, Bijeljac-Babic, Herold, Weissenborn \& Nazzi, 2009, for a review).

Given its importance in infants' perception of language, one might ask how prosodic information interacts with the construction and processing of stable phonetic representations at the onset of lexical development. In this article we aim to study this interaction by examining how the location of stress in disyllabic words influences the level of syllable-onset consonant detail in young English-learning children. More specifically, we focus on the interactions between stress position and phonetic contrast in lexical representations by examining the interaction between the stress pattern (trochaic versus iambic) and position of the phonetic contrast (onset of the initial syllable versus onset of the second syllable) in disyllabic stimuli. Using these stimuli we engage 20-24-month-old children in a novel word learning task. This age range was selected to examine the interaction between supra-segmental and phonetic information in word learning without having to confront temporary inabilities to access or to build phonetic representations. In addition, around that age children are actively engaged in lexical learning but are still expanding their lexicon, as shown by average scores on the Oxford Communicative Development Inventory approaching $70 \%$ of the 416 words in comprehension and $30 \%$ in production (Hamilton, Plunkett \& Schafer, 2000).

In English the acoustic realization of stress and its underpinning phonological system provide an interesting opportunity to look into the interactions between segmental and supra-segmental representations in the emerging lexicon, for it places the young English learner in a situation of poor 'acoustic and phonetic transparency', whose level is defined as 'the ease with which a segment can be identified as distinct from another competing candidate in a language' (Sebastián-Gallés, Dupoux, Segui \& Mehler, 1992, p. 19). According to these authors, the level of transparency would be hampered by different factors such as variable and contrastive stress, ambisyllabicity and vowel reduction, all aspects that are present in English (Anderson \& Jones, 1974; Brown, 1977; Gimson, 1989; Ladefoged, 1993; Treiman \& Danis, 1988; Vihman, DePaolis \& Davis, 1998) and therefore contribute to a low degree of acoustic-phonetic transparency in unstressed syllables. Rules of stress assignment in English lead to disyllabic words being mainly stressed on the first syllable, resulting in trochaic patterns such as in the word EFfort (Cutler \& Carter, 1987). Iambic patterns, where stressed syllables are preceded by an unstressed syllable such as in efFECT, are much rarer in English.

Thus far only a few studies have specifically addressed the interactions between stress assignment and the phonetic specificity of lexical representations. Vihman et al. (2004) followed up on studies by Hallé and BoyssonBardies (1994, 1996), showing that 11-month-old French-speaking infants were able to identify familiar words that had their initial consonants changed, but not their medial consonants changed. Hallé and BoyssonBardies suggested that this was because initial unaccented syllables are not fully specified at 11 months of age, and Vihman et al. (2004) argued that this could be due to the importance of stressed syllables in word representations, as in French the stress (or rather fixed accent) nearly always falls on the last syllable of words (Di Cristo, 1998). Therefore, as the stress pattern in English is largely trochaic, Vihman et al. (2004) predicted that (at least in trochaic words) the recognition of familiar words would be impaired if the initial consonant was changed, but not if the change was made on a medial consonant. This prediction was indeed validated, but the study also revealed that recognition was completely blocked when the initial consonant was changed in English (e.g. vunny instead of bunny), whereas the medial consonant change in the French study (balane instead of banane) did not have such a marked effect. Vihman et al. (2004) argued that this was an indication of the crucial role that word-initial phonemes play in word recognition, and that segmental information is better represented in stressed than unstressed syllables ${ }^{1}$ (also see Curtin, 2010, for a recent study showing 14-month-olds' abilities to encode phonetic information in stressed syllables).

However, Johnson (2005) alleged that infants would require access to the phonetic detail of unstressed syllables to extract iambic word forms from the speech stream. Using the word segmentation paradigm developed by Jusczyk and Aslin (1995), she familiarized 10.5-month-old infants with made-up iambic words (e.g. giNOME). The infants were then tested using passages containing exact representations of the familiarized words, some novel words, or the familiarized words with a different initial consonant (e.g. piNOME). While the infants were found to listen longer to the familiarized words than to the novel words, there was no such effect

\footnotetext{
${ }^{1}$ In further discussion we will refer only to the processing and representations of content words, and deliberately ignore function words. Shi, Werker and Cutler (2006) have shown that at 13 months, English-learning infants possess a detailed phonetic representation of unstressed functors, which suggests that the phonetic specificity of words also depends on the frequency of the encountered items, but for clarity purposes we will not discuss this issue here.
} 
when the initial consonant of the familiarized words was changed. As the infants' behaviour was modulated by the change in the initial consonant, Johnson (2005) concluded that the phonetic representation of unstressed syllables is sufficiently detailed to encode a word-initial consonant contrast.

Although there would appear to be a direct contrast between the findings of Johnson (2005) and Vihman et al. (2004), differences in the design of the two studies make it difficult to draw any concrete conclusions on the interaction between supra-segmental and segmental representations. While Vihman et al. presented trochaic forms, Johnson used iambic forms, and also Vihman et al. used a word recognition task whereas Johnson used a novel word forms segmentation task. We must also take Johnson's use of word-initial consonant contrasts into consideration, as Vihman et al. suggest that this position plays a key role in word processing. Therefore it is always possible that the disparity between their findings could be accounted for by the differences in experimental factors, tapping onto different levels of processing and/or representations.

In this study we aim to contribute to this literature by examining the link between phonetic and supra-segmental processing within the context of new word learning. Specifically, we wish to examine whether the detection of phonetic contrasts is modulated by three potential factors: the stress of the syllable in which they are embedded, whether they are word-initial or -medial, and whether they are found in the (more frequent) trochaic or in the iambic stress pattern.

The lack of clarity regarding the first of these factors was discussed above. For the second factor, the relative importance of word onsets over offsets in adult word processing has been emphasized in a number of studies (e.g. Content, Kearns \& Frauenfelder, 2001; MarslenWilson, 1987). However, it is questionable whether children exhibit this sensitivity at an early age, as part of an in-built property of speech processing mechanisms. Recent studies suggest otherwise, as equal sensitivity to syllable onset or coda was reported in a mispronunciation detection task with English-learning 14-22-montholds (Swingley, 2009), and in a word learning task with French-learning 20-month-olds (Nazzi \& Bertoncini, 2009). These results suggest that 20 - to 24 -month-olds could be equally sensitive to phonetic contrasts located in either word-initial or -medial position.

Finally, regarding the third factor of interest to this study, it must be noted that in English the privileged status of the trochaic over the iambic stress pattern is well established, with strong syllable onsets providing preferential cues for word segmentation (Cutler \& Butterfield, 1992; Cutler \& Norris, 1988; Echols, Crowhurst \& Childers, 1997), an efficient strategy given that most of the English lexicon is made up of trochaic words. Moreover, there is evidence for the emergence of an early trochaic bias between 6 and 9 months in young Englishlearning infants (Jusczyk, Cutler \& Redanz, 1993; Jus- czyk et al., 1999), and for an advantage of trochaic over iambic forms in word segmentation tasks between 7.5 and 13.5 months (Jusczyk et al., 1999; Nazzi, Dilley, Jusczyk, Stattuck-Hufnagel \& Jusczyk, 2005). In addition, stress patterns also impact on children's productions during their second year of life, as seen by a tendency to omit initial unstressed syllables, saying for example NAna instead of baNAna (Allen \& Hawkins, 1980; Echols \& Newport, 1992; Vihman et al., 1998). In sum, these studies indicate a possible trochaic bias in early word processing or representation developed from repeated exposure to the stress pattern regularities of English. ${ }^{2}$ Accordingly, one could expect the phonetic representations of 20 - to 24 -month-old children to be more detailed for trochaic than iambic sequences.

In a joint design, two experiments were conducted to examine how children access phonetic information in newly learnt words, depending on the manipulation of the three factors under scrutiny: syllable stress, word position, and word stress pattern. In both experiments children were presented with pairs of disyllabic pseudowords, half produced with a trochaic pattern, half with an iambic pattern. In Experiment 1, pseudo-word pairs differed by a consonant located at the onset of the first syllable (word-initial), while in Experiment 2 the differing consonant was at the onset of the second syllable (wordmedial).

\section{Experiment 1}

Twenty- to 24-month-old children were engaged in a variant of the word learning procedure developed by Nazzi and Gopnik (2001; see also Havy \& Nazzi, 2009), in which they were presented with novel objects labelled using pairs of pseudo-words that differed only on their initial consonants. These pseudo-word pairs were disyllabic, with half of the pairs produced with a trochaic pattern, and the other half with an iambic pattern (/puisə/ versus / tu: $\int \partial /$, or /pə'ऽəu/ versus

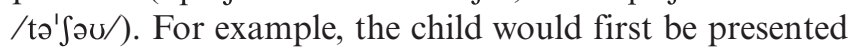
with an object labelled a / pu: $\int \mathrm{\partial} /$, and then presented with a different object labelled a $/$ tu: $\int \partial /$. The experimenter then introduces a third novel object also called a $/ \mathrm{pu}: \int \mathrm{s} /$, and asks the child to give him or her 'the other $/ \mathrm{pu}: \int \partial /$ '.

\footnotetext{
${ }^{2}$ Iambic words are also quite rare in children's early vocabulary, as they are in the English lexicon in general. A count in the Oxford Communicative Developmental Inventory (Hamilton et al., 2000), which includes 416 words, shows that the vast majority of the words intended to describe most of the vocabulary of young children in perception and production until 25 months is made up of trochaic words. Out of the 352 content words (excluding 12 onomatopoeias and 40 function words), 225 are monosyllabic, 119 are disyllabic, and 20 have three or more syllables. Out of the 119 disyllabic words, 112 are trochaic (the exceptions being giraffe, balloon, outside, asleep, today, inside). Out of the 20 words containing three or more syllables, 15 are stress initial (the exceptions being tomorrow, policeman, pyjamas, banana and refrigerator).
} 
Table 1 The percentage of correct identification of the target items in Experiment 1 with trochaic (TR) or iambic (IM) stress patterns. Bold items are those with a sonorant pivotal consonant (leading to more ambisyllabicity)

\begin{tabular}{|c|c|c|c|c|}
\hline Trochaic version & Iambic version & contrast & $\mathrm{TR}$ & IM \\
\hline 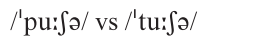 & 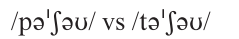 & place & 80.0 & 38.5 \\
\hline /'go:dzI/ vs /'do:dzI/ & /gə'dzi:/ vs /do'dzii/ & place & 66.7 & 69.2 \\
\hline /'du:bi/ vs. /'gu:bi/ & /də'bi:/ vs /ga'bi:/ & place & 64.3 & 43.8 \\
\hline /'pi:lə/vs /'bi:lə/ & /pı'la:s/vs /bI'la:ı/ & voice & 42.9 & 46.7 \\
\hline /'bəusə/vs /'pəusə/ & /bə'sa:z/vs /pə'sa:d/ & voice & 78.6 & 57.1 \\
\hline /'pəunət/ vs /'bəunət/ & /pə'nıt/vs /bə'nıt/ & voice & 33.3 & 43.8 \\
\hline
\end{tabular}

For children to succeed in this task they must be able to learn the label/referent pairings and also distinguish between the phonetic contrast that separates the two original labels. This procedure provides ecological plausibility as children are actively involved in manipulating new objects and associating them with novel words (see also Nazzi, 2005; Nazzi et al., 2009; Nazzi \& Bertoncini, 2009).

\section{Method}

\section{Participants}

Thirty children (including 13 girls) with an average age of 22.5 months (from 19.5 to 25.7 ) were successfully tested in this experiment. All were raised in English-speaking families, had no recorded auditory or developmental problems, and were no more than 6 weeks premature. Scores from the Oxford CDI averaged $44.0 \%$ in production (from 3.8\% to $100 \%$ ) and $72.05 \%$ in comprehension (from $28.4 \%$ to $100 \%$ ). From the 30 tested children, 24 completed all eight trials of the experiment, four completed seven trials and two completed six trials. Incomplete trials were due to the child either giving no answer, or picking up or putting both of the labelled objects into the pot. An additional 25 children were also tested, but were rejected due to a systematic bias in the object selection from the left or right (13); ${ }^{3}$ lack of participation or non-completion of a minimum of six trials (seven); distraction (one) or because they systematically put both of the objects in the pot (one). Three children were also excluded due to Oxford CDI scores below the $10^{\text {th }}$ percentile of the published norms (in production: $0.96 \%$ and $1.44 \%$ at 20 months, and $1.92 \%$ at 20.5 months).

\section{Stimuli}

Three novel objects were used for each of the eight test trials. Each of these 24 unique small objects was selected such that they would be unfamiliar to the children, and so would not already be associated with a name. All of the

\footnotetext{
${ }^{3}$ Re-analyses of data including children who always chose an object on the same side, and those who performed poorly at the Oxford CDI, gave exactly the same pattern of results, in Experiments 1 and 2.
}

sets of three objects were physically distinct, differing in shape, colour, and texture in an effort to equalize their perceptual distance. For each test trial a pair of non-words was used to label the first two novel objects, with each pair differing by a single feature (place or voice) initial consonant contrast (for example/pu: $\int \partial /$ versus / tu: $\int \partial /$ ). Nonwords were constructed such that they could be easily pronounced in either a trochaic or an iambic template (see Table 1). It must be noted, however, that the phonology of English is such that the quality of vowels can be modified depending on the location of stress (Hayes, 1995); therefore not all versions of the pairs, trochaic versus iambic, are necessarily phonetically equivalent.

Prior to the eight test trials, two similar warm-up trials were presented. In the first one the two initial objects consisted of a toy cow and a toy car, labelled respectively an animal and a car. The third of the objects was a toy pig, also labelled an animal. In the second warm-up, one of the objects of the pair was a toy dog, labelled a $d o g$, while the other was a novel object, labelled a /grk/. The third of the objects was also novel and labelled a /grk/.

\section{Procedure}

Each child was tested individually in the BabyLab facility of the School of Psychology, after active consent had been obtained from the parents or caregivers. The session was filmed for scoring purposes, using a Sony Handy Cam DCR - HC35E. The procedure was an adaptation of the categorization task used by Nazzi (2005), but in this version the child was not asked to categorize objects, but simply to associate the object to its newly learnt label (see Havy \& Nazzi, 2009). The warm-up trials were identical to the test trials except that the presentation of the objects and the identification question were repeated if the child's initial response was incorrect (although the child was not told that the answer was incorrect). All 30 children responded correctly to their first or second attempt in the warm-up trials.

Each of the trials was composed of a presentation phase, followed by an identification question. In the presentation phase two objects were given to the child, one at a time, with the child encouraged to manipulate the object for a few seconds before placing it on the table in front of them. Within each trial, the objects were ar- 
ranged on the table in a left-to-right sequence (child's perspective) in order to minimize memory load. The experimenter (a British English native speaker, naive to the aims and hypotheses of the experiment) spoke while presenting each object, saying (for example): 'Look! A $\Lambda_{\text {tu }} \int \mathrm{\partial} /$. This is a $/$ tu: $\int \partial /$. Do you want to play with the $\Lambda$ tu: $\int 2 /$ ? Yes, play with the $/$ tu: $\int 2 /$. See this $/$ tu: $\int 2 /$ ? All right, let's put the $/$ tu: $\int \mathrm{g} /$ on the table. Here.' Each object was named between five and seven times in the presentation phase. These two objects were named with two phonemically distinct non-words, such as $/$ tu: $\int a /$ versus $/ \mathrm{pu}: \int \mathrm{\partial} /$, sharing the same stress pattern (both were produced with either the trochaic or iambic template).

After the presentation phase, the experimenter tested lexical recognition by introducing a third object, naming it twice, and putting this object in a pot placed in the middle of the table at equal distance from the first two objects. For example, if the first object was named a $/$ tu: $\int \mathrm{a} /$, and the second a $/ \mathrm{pu}: \int 2 /$, the third object could be named a $/$ tu: $\int a /$ (or a $/$ pu: $\int a /$ ). The experimenter asked the child to put 'the other $/ \mathrm{tu}_{\mathrm{S}} \mathrm{\partial} /$ ' in the pot. While waiting for the response, the experimenter looked at either the child's face or the object in the pot in order to avoid influencing the child's response. After the child's response, positive feedback was provided regardless of the choice made. Successful performance corresponded to the selection of the similarly labelled object.

The order of presentation of the trials and the labels associated with each object in the triad, the position on the table and order of presentation of the objects were counterbalanced between participants. Each child was presented with four trochaic and four iambic pairs of object labels, with a pseudo-random order of presentation so that no more than three consecutive pairs could have the same stress pattern. Children's productive and receptive vocabulary was assessed using the vocabulary part of the British equivalent of the CDI Toddlers (Hamilton et al., 2000).

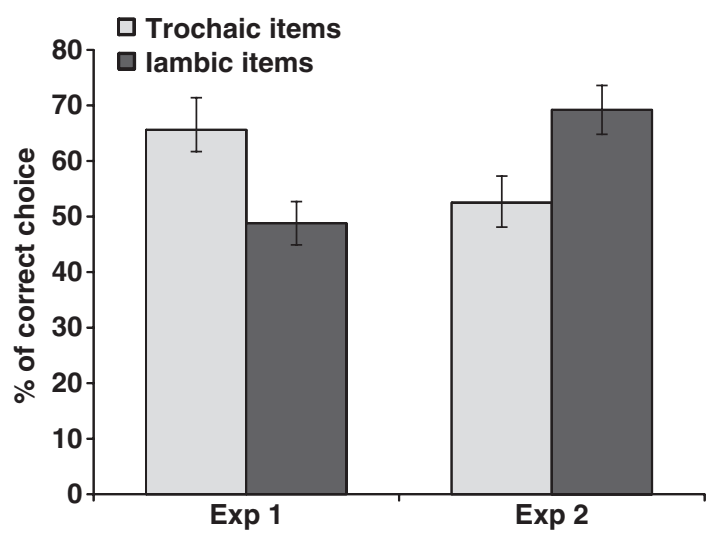

Figure 1 Percentage of correct responses for trochaic and iambic items in Experiment 1 (contrast on the first consonant) and Experiment 2 (contrast on the medial consonant).

\section{Results and discussion}

The average rate of correct target item identification (success rate) of the 30 participants was $57.5 \%$, significantly greater than the $50 \%$ chance rate $(t(29)=2.14$, $p=.040$ ). ANOVA analyses of success rates were conducted with stress condition (trochaic versus iambic) and consonant contrast type (voice versus place) as withinparticipant factors. No main effect of consonant contrast type was found $(F(1,29)<1)$, nor did this factor significantly interact with the factor of stress condition $(F(1$, $29)<1)$, therefore contrast type will not be included in further analyses. Stress pattern was shown to have a significant effect over success rate $(F(1,29)=5.53, p=$ .026 ), with performance in the trochaic condition higher than in the iambic condition, as can be seen on Figure 1 (see also the details of results by items in Table 1). Planned comparisons showed that participants performed above chance level in the trochaic condition $(65.6 \%, t(29)=2.68, p=.012)$, but were at chance level in the iambic condition $(48.6 \%, t(29)<1)$. Tests of correlation between the success rates of stimuli with trochaic and iambic stress patterns were not significant $(r=-.05$, $p=.80$ ). There was no correlation between overall success rate in the task and either CDI production $(r=.34$, $p=.067)$ or comprehension $(r=.28, p=.12)$ scores. Age correlated with the CDI scores in production $(r=.47, p=.008)$, but the correlation between age and the CDI scores in comprehension only approached significance $(r=.32, p=.081)$, possibly because of a ceiling effect.

Further analyses, comparing success rates for individual pseudo-word pairs, shown in Table 1, highlight considerable variability between stimuli pairs, ranging from 33.3 to $81.3 \%$. To account for this variability we explored two factors that were not controlled in the original design: the possibility of embedded familiar words (as suggested to us by the Editor), and the degree of ambisyllabicity in the pivotal intervocalic consonant between first and second syllable nuclei.

When considering embedded words it is possible that prior knowledge of familiar words embedded within our non-word stimuli could have coloured the representation of the to-be-discriminated items. For example, the word show is embedded in the pair /pə'Jəo/vs. /to'Sou/, and if extracted, leaves a lexically acceptable residue - according to the Possible Word Constraint (PWC) formulated by Norris, McQueen, Cutler and Butterfield (1997; Johnson, Jusczyk, Cutler \& Norris, 2003), which states that a new word cannot be segmented if it leaves a single consonant as a residue. With this in mind, an examination of the stimuli reveals that the word show is also embedded - to a lesser extent - in / pu: $\int \mathrm{a} / \mathrm{vs}$. $/ \mathrm{tu}: \mathrm{Sa} /$, together with the words poo and two. Four similar cases were also identified in our stimuli: mess and toe in /ka'mes/ vs. /ta'mes/ and /kaumes/ vs. Ataumes/, bee and do in /da'bi:/vs. /ga'bi/, pee and bee in /piila/vs. /bi:ld/, key in /gippou/vs. /kippou/. Finally, the word 
doughnut could sound like a mispronunciation of /pounat/vs. /bounat/. Although some of these words are not listed in the Oxford CDI (mess, doughnut, poo, pee, two and $d o$ ), they are likely to have been heard by children by 23 months. However, post-hoc analyses revealed no significant differences in success rates for the eight pairs of stimuli with familiar embedded words $(60.7 \%)$ and the remaining eight pairs of non-words without embedded words $(58.6 \%$; paired $t$-test, $t(29)<1)$.

Discounting the possibility that embedded familiar words might affect success rates, we now turn to ambisyllabicity. As defined by Lahiri (2001, p. 1351): 'Ambisyllabicity results from the attraction of the first consonantal onset of an unstressed syllable to form the coda of the preceding syllable. This consonant then becomes ambisyllabic, since it belongs both to the onset and the coda of the two syllables'. For example, the $/ \mathrm{m} /$ in lemon belongs to both syllables. Whether or not a consonant is ambisyllabic in English depends on many factors: ambisyllabicity is much more frequent in trochaic words than iambic ones (e.g. Trammel, 1993, p. 313), it is more likely to be found if the pivotal consonant is a sonorant rather than an obstruent, and if the preceding vowel is short rather than long (Treiman, Bowey \& Bourassa, 2002). With these definitions in mind it appears that our trochaic pairs are more likely to be analysable as including an ambisyllabic medial consonant than are the iambic pairs. In addition, while all trochaic stimuli had long initial vowels, three contained sonorant medial consonants (/kəumes/ vs. /taumes', / pi:la/ vs. /'billa/ and /paunat/ vs. /'baunat/), which could lead to increased ambisyllabicity over the five remaining pairs which had obstruent medial consonants.

To examine the effect of potential ambisyllabicity on success rates, an ANOVA was conducted using withinparticipant factors of stress pattern (trochaic versus iambic) and ambisyllabicity (sonorant versus obstruent pivotal consonant). Due to the relative paucity of stimuli pairs with sonorant intervocalic consonants and the random distribution of stimuli across participants, only 14 out of the 30 children presented with both types of stimuli were included in this analysis. This showed a marginal effect of ambisyllabicity $(F(1,13)=4.33$, $p=.058$ ), with stimuli containing the less ambisyllabic obstruent intervocalic consonants having a higher average success rate $(61.9 \%)$ than those with the more ambisyllabic sonorant consonants $(46.3 \%)$. No interaction was found between stress pattern and ambisyllabicity $(F(1,13)=2.34, p=.15)$.

To summarize, in this experiment we examined 20- to 24-month-old children's phonetic encoding of a wordinitial consonant contrast in trochaic and iambic carrier words using a word learning task. The results showed that children were able to distinguish the initial phonemic contrast, but only when embedded within a trochaic carrier, and not when the initial syllable of the carrier was unstressed. This finding suggests that the supra-segmental properties of English continue to affect the accuracy of children's representations of word forms by the end of their second year. Further implications of this finding will be discussed when they can be combined with those of Experiment 2, where the tested phonetic contrast is placed at the start of the second syllable. This will allow a fuller understanding of how word position, syllable stress, and word stress pattern modulate phonetic encoding in early word learning.

\section{Experiment 2}

In this experiment the procedure used in Experiment 1 was repeated but in this case the phonemic contrast between non-words was positioned on the pivotal intervocalic consonant.

\section{Method}

\section{Participants}

Thirty children (including 16 girls) with an average age of 21.2 months (from 18.3 to 23.8) were successfully tested in this task. These children were selected using the same criteria as those of Experiment 1, and scored an average of $40.2 \%$ in the production Oxford CDI (from $3.6 \%$ to $96.4 \%$ ), and $69.0 \%$ in comprehension (from $35.1 \%$ to $100 \%$ ). Out of these 30 children, 11 completed the eight trials, 17 completed seven trials and two completed six trials. A further 14 children were tested but were rejected because they showed a systematic bias to pick up the object on one side (five), did not complete a minimum of six trials (five), chose to 'tidy up' all the objects (one), or systematically put both objects in the pot (one). We also excluded two children who scored below the 10th percentile of the published norms of the Oxford CDI (in production: $1.9 \%$ at 21 months and $2.2 \%$ at 23 months).

\section{Stimuli}

Test stimuli were constructed in the same manner as in Experiment 1, differing only in the location of the phonemic contrast, which here is located on the pivotal intervocalic consonant. Moreover, the initial syllables carrying the consonant used for the phonemic contrast in Experiment 1 were reused in this experiment, moved from the first to the second syllable position of the nonwords. For example, the contrastive pair $/ \mathrm{pu}: \int \mathrm{J} / \mathrm{vs}$.

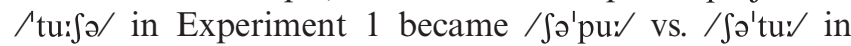
Experiment 2. The only exceptions to this were the /paunat/vs. /bounət/ and /pa'nıt/vs. /ba'nıt/ pairs (voice contrast) in Experiment 1 transforming into $/$ nu:d $/$ vs.

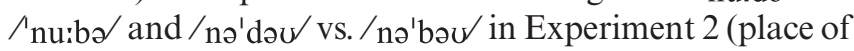
articulation contrast), due to experimenter error. Wherever possible non-word pairs in this experiment were constructed simply by reversing the syllables of stimuli from Experiment 1, although this was possible only for three out of the eight stimuli pairs. For example, /'koumes' 
Table 2 The percentage of correct identification of the target items in Experiment 2 with trochaic (TR) or iambic (IM) stress patterns. Bold items are those with an ambisyllabic pivotal consonant

\begin{tabular}{|c|c|c|c|c|}
\hline Trochaic version & Iambic version & contrast & TR & IM \\
\hline /'dzi:gəu/ vs /'dzi:dəu/ & /dz' $I^{\prime} g o: / v s ~ / d z I^{\prime} d o: /$ & place & 72.2 & 66.7 \\
\hline /'Soupu/vs /'Soutu/ & /Sa'pu:/vs / $\int \partial^{\prime}$ tu:/ & place & 70.0 & 78.9 \\
\hline /'mekə/ vs /'metə/ & /mə'kəu/vs /mə'təu/ & place & 60.0 & 61.1 \\
\hline /'nuida/ vs /'nu:bə/ & /nə'dəu/vs /nə'bəu/ & place & 33.3 & 54.5 \\
\hline /'sæbə/ vs /'sæpə/ & /sæ'bəu/vs /sæ'pəu/ & voice & 20.0 & 61.1 \\
\hline$/ / 1 \varepsilon \mathrm{pI} / \mathrm{vs} / ' 1 \varepsilon \mathrm{bI} /$ & /lə'pi:/vs /lə'bi:/ & voice & 40.0 & 80.0 \\
\hline
\end{tabular}

vs. / toumes/in Experiment 1 became $/ \mathrm{mek} /$ vs. $/ \mathrm{met} / \mathrm{in}$ Experiment 2.

\section{Procedure}

The procedure was identical to that used in Experiment 1.

\section{Results}

The average success rate across the 30 participants was $60.6 \%$, significantly above the chance level of $50 \%(t(29)$ $=3.96, p<.001)$. Further ANOVA analyses of success rate were also conducted with within-participant factors of stress pattern (trochaic versus iambic) and type of consonant contrast (voice versus place). As in Experiment 1 , there was no significant main effect of consonant contrast $(F(1,29)<1)$, nor did it interact with stress pattern $(F(1,29)<1)$. Stress pattern was found to have a significant effect over success rates in Experiment 2 ( $F(1$, 29) $=5.09 ; p=.032$ ), with participants performing better in the iambic than in the trochaic condition (see Figure 1, and Table 2 for the results by items). Further analyses showed that children performed above chance only in the iambic condition $(69.2 \%, t(29)=4.38, p<.001)$, not in the trochaic condition $(52.5 \%, t(29)<1)$, the opposite pattern to that found in Experiment 1. No significant correlation was found between success rates in the trochaic and iambic stress patterns $(r=-.30, p=.10)$, nor between overall success rate and CDI production $(r=$ -.03) or comprehension $(r=.18)$ scores. Children's age correlated with CDI scores in production $(r=.56, p=$ $.001)$ and in comprehension $(r=.56, p=.001)$.

As in Experiment 1, analyses of success rate variability between non-word pairs were conducted, investigating the possible effects of embedded words and ambisyllabicity. Five non-word pairs were found to contain embedded words, show, poo and two in / Soupu/ vs. / Soutu/ and in / So'pu:/ vs. / So'tu:/, bee and pee in /lo'pi// vs. /o'bi:/, key in /po'gi:/ vs. /po'ki//, and bed in /bedu/ vs. $/ \mathrm{b} \varepsilon \mathrm{gu} /$. A $t$-test comparing children's success rates between these five pairs $(66.1 \%)$ and the 11 pairs without embedded words $(57.3 \%)$ was not significant $(t(29)=1.26, p=.22)$. Therefore, as in Experiment 1, there is no evidence to suggest that the children's knowledge of embedded words had a significant effect over their success rates.
An examination of potentially ambisyllabic stimuli in Experiment 2 highlighted differences in initial vowel length, with four trochaic pairs having initial short

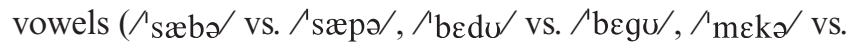
$/ \mathrm{met} /$ and $/ 1 \mathrm{ep} / \mathrm{vs}$. $/ 1 \varepsilon \mathrm{bi} /$ ) and four initial long vowels. It is worth noticing here that the ambisyllabicity of the pivotal consonant was mainly related to the nature of the pivotal consonant in Experiment 1, and to the length of the preceding vowel in Experiment 2. In addition, as all the medial consonants in the trochaic items were obstruent in Experiment 2, it was not possible to analyse the potential ambisyllabic effect of sonorant/obstruent consonant types, as was conducted in Experiment 1.

As ambisyllabicity should be greater for stimuli with initial short vowels than long vowels, a post-hoc ANOVA analysis of individual success rates was conducted using within-participant factors of word stress pattern (trochaic versus iambic) and ambisyllabicity (short versus long vowels). This analysis did not reveal any significant effect of ambisyllabicity on success rates $(F(1,29)=2.52$, $p=.12$ ), although items with the long vowels (leading to less ambisyllabicity) tended to be more successful $(66.7 \%)$ than those with the short vowels (leading to more ambisyllabicity; $56.7 \%$ ). There was no interaction between stress pattern and degree of ambisyllabicity $(F(1$, 29) $=2.73, p=.11$; see Figure 2).

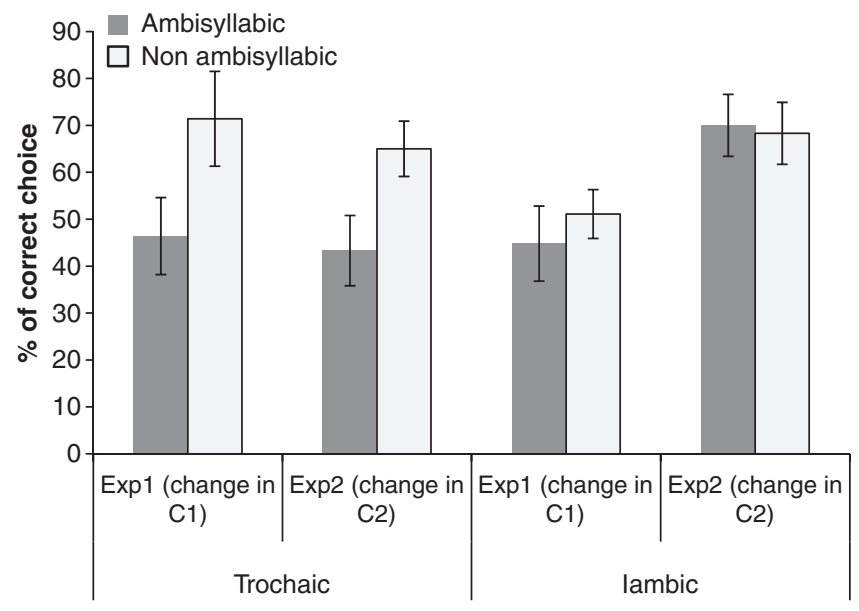

Figure 2 Percentage of correct responses for trochaic and iambic items in Experiments 1 and 2 as a function of ambisyllabicity of the medial consonant. 
Table 3 Mean percentages (and standard deviations) of misses, false alarms and total errors (false alarms and misses) collected in the adult same/different decision task, together with mean $A^{\prime}$ values (and standard deviations). A percentage of $4.17 \%$ misses corresponds to an average of 0.66 items missed out of the 16 items in this category (per participant)

\begin{tabular}{llccccrrrr}
\hline Stress pattern & Contrast & \% of misses & $S D$ & \% of false alarms & $S D$ & \% of total errors & SD & $A^{\prime}$ & $S D$ \\
\hline trochaic & initial & 4.17 & 5.10 & 2.53 & 4.63 & 3.34 & 3.63 & 0.983 & 0.020 \\
iambic & initial & 9.31 & 5.91 & 5.42 & 7.03 & 7.34 & 3.91 & 0.961 & 0.022 \\
trochaic & medial & 4.25 & 4.65 & 0.83 & 2.20 & 2.53 & 2.74 & 0.987 & 0.014 \\
iambic & medial & 5.00 & 6.76 & 0.42 & 1.61 & 2.77 & 3.65 & 0.986 & 0.018 \\
\hline
\end{tabular}

\section{Comparison of the results of Experiments 1 and 2}

By combining the results of Experiments 1 and 2 we made a direct comparison of phonemic discrimination success rates with a between-participants factor of word position (phonemic contrast being word-initial versus word-medial) and a within-participant factor of stress pattern (trochaic versus iambic). The effect of the third variable, namely the stress status of the syllable containing the phonemic contrast, was represented by an interaction between word position and stress pattern. This analysis revealed no main effects; neither the effect of word position $(F 1(1,58)<1)$ nor stress pattern reached significance $(F 1(1,58)<1)$. However, there was a significant interaction between stress pattern and position in the word $(F 1(1,58)=10.60, p=.002)$, showing that participants were more successful with trochaic stimuli when the phonemic contrast was word-initial, and with iambic stimuli when the phonemic contrast was word-medial.

When considering the variability in success rates between individual non-word pairs, there was a consistent, yet marginal, effect of ambisyllabicity noted in both experiments. Extending this method of analysis across the results of the two experiments we conducted an ANOVA on individual success rates with experiment (1 or 2) as a between-participants factor and stress pattern (trochaic or iambic) and ambisyllabicity (stimuli prevalent to ambisyllabicity or not) as within-participant factors. This revealed an interaction between ambisyllabicity and stress pattern $(F(1,41)=4.47, p=.04)$, with ambisyllabicity reducing success rates in trochaic stimuli (ambisyllabic: $68.2 \%$, non-ambisyllabic: $44.9 \%$ ), but not in iambic stimuli (ambisyllabic: 58.5\%, non-ambisyllabic: 59.8\%).

Overall the combined results from both experiments indicate that 20- to 24-month-old children are able to distinguish phonetic contrasts only in stressed syllables, and that even this ability is lost if the stressed syllable in trochaic words is ambisyllabic.

\section{Discussion}

This experiment revealed that when the phonemic contrast between non-words was located on a medial consonant, children were better at distinguishing those words when their stress pattern was iambic rather than trochaic. By combining the results of Experiments 1 and 2 we learn that the consonantal phonemic contrast is salient only when its syllabic carrier is stressed. This would appear to be irrespective of the location of the stressed syllable, or the stress pattern of the word.

Before discussing the general implications of these results, it was important to consider the possibility that the pattern of results obtained so far could be explained by the acoustic characteristics of the stimuli. It is possible that the stress patterns and/or of the to-be-discriminated contrasts were realized such that only the contrasts embedded in stressed syllables could be distinguished. To test for this possibility we randomly selected audio recordings of two testing sessions for each experiment, with the constraint that these recordings would cover the entire stimuli set for both experiments. Then, for each pair we extracted the sentences containing the first two occurrences of both to-be-learned pseudo-words (for example: 'I have a / Səupu/!'; 'Do you want to play with that $/$ Soupu/?'), plus the two occurrences of the target pseudo-word (for example: 'Now I have another /Sautu/!'; 'Can you put the other $/$ Sautu/in the pot for me, please?'). A total of 96 pairs of sentences were extracted, and presented to a group of 15 naive English-speaking adults (including eight females; mean age 24.2 years) in a same/different decision task and a transcription task. In the former task, participants were presented with the two sentences describing one of the learned objects followed by the two sentences describing the target object. The participants were then asked to decide whether the two object names were the same or different by pressing appropriate keys. Of the 64 pairs of object names presented, half were similar and half different. The error rate with these adults was only $7.52 \%$, with $2.32 \%(S D=1.86)$ errors on false alarms, and $5.20 \%(S D=2.86)$ errors on misses. Sensitivity $\left(A^{\prime}\right)$ measure of signal detection was computed for each participant and each condition (see Table 3). Adults scored very high on $A^{\prime}$ values, ranging from 0.93 to 1 , showing discrimination close to ceiling level. An ANOVA with phonemic contrast position (first or medial consonant) and word stress pattern (iambic or trochaic) as repeated measures was conducted on $A^{\prime}$. In contrast to the experiments with children, these analyses did not reveal any significant interaction between contrast position and word-stress pattern in adults $(F(1$, $14)=2.73, p=.12)$. However, word position had a main significant effect $(F(1,14)=19.35, p=.001)$, because of lower values of $A^{\prime}$ when the contrast was word-initial (.972) than word-medial (.987). Similarly, stress pattern was found to have a main significant effect $(F(1$, 
14) $=5.53, p=.034)$, due to lower $A^{\prime}$ values for iambic (.974) than for trochaic sequences (.985).

After the discrimination task, our adult participants were asked to transcribe 96 pairs of sentences, each consisting of two utterances describing a particular object. Given the opacity of the English orthographic system, vowel transcriptions were highly variable, with the item /ba'gu/ transcribed variously as begoo, begu, bagu, bergue, bugoo, bagooe, begou, bugue. However, as we were primarily interested in the transcription of the consonantal contrast, transcriptions were reported as correct if both syllables of the item were represented, and the consonant of interest was correctly transcribed. Using these criteria only $2.36 \%(S D=2.79)$ of transcriptions were erroneous, showing that all the contrasts were easily perceived by our adult participants (see Table 3). Moreover, these few errors were equally distributed across all of the factors under analysis.

The results of both the adult discrimination and transcription experiments show that adults could distinguish our phonemic contrasts at near ceiling level, and that they were no better at detecting contrasts in stressed syllables than unstressed syllables. Therefore it is unlikely that children were prevented from perceiving the phonemic contrast in unstressed syllables due to the acoustic characteristics of the stimuli.

In a final comparison we also tested a group of 12 adults (mean age 32.8 years, including eight females) in a word learning task similar to that used with the children using the recorded sentences extracted for the adult same/different experiment. Participants first heard two sentences containing the non-word label for 'object 1', followed by two sentences containing the similar, but phonemically contrasted, non-word label for 'object 2'. After this 'learning phase' the participants heard two sentences describing a target item corresponding to the label of one of the learned objects, and were asked to make a speeded judgment as to whether the target was the same as object 1 or 2 . The presentation order of the 32 object pairs used in this experiment was randomized across participants. Error rates were too low to allow any informative analyses (mean $0.98 \%$ ). The only significant reaction time effect was an interaction between word stress pattern and phonemic contrast position $(F(1$, $11)=6.32, p=.029)$. This revealed that one particular combination of conditions was significantly slower than the other three, namely the initial consonant contrast in iambic non-words. Therefore, although adults had slightly greater difficulty in differentiating phonemic contrasts in unstressed syllables, this was specific to iambic words, and was not generalized across both iambic and trochaic words, as found with children.

\section{General discussion}

The aim of this study was to investigate the interaction between supra-segmental information and phonetic specificity of early lexical processing. To this end, we tested 20- to 24-month-old English-learning children in a word learning task where the to-be-learnt items differed by a single consonant located either in the first (Experiment 1) or second syllable onset (Experiment 2) in both trochaic and iambic word forms. These experiments were designed to investigate the interaction between three factors. First, the position of the phonemic contrast (word-initial or word-medial) allowed us to test the possibility that word-initial position might not be as important in children as it is in adults' word recognition (e.g. Swingley, 2009). For the stress status of the contrastbearing syllable (stressed versus unstressed) we predicted that stressed syllables would lead to better acoustic/phonetic processing than unstressed ones (e.g. Sebastián-Gallés et al., 1992). Finally, for the stress pattern of the word (trochaic versus iambic) we wished to examine whether the trochaic bias found in both 7.5month-old English-learning infants (e.g. Jusczyk et al., 1999) and English-speaking adults' segmentation (e.g. Cutler \& Norris, 1988) might also affect phonetic processing in 20- to 24-month-olds.

One of the findings of this study was that the absolute position of the phonemic contrast, being either word-initial or word-medial, had no effect upon the children's ability to discriminate between consonants. This was similar to those of a mispronunciation detection task with 14- to 22-month-old English-learning children (Swingley, 2009), and a word learning task with 20-month-old French-learning children (Nazzi \& Bertoncini, 2009), which also failed to find processing asymmetries between word-initial and non-initial contrasts. It is possible that the word learning task used by ourselves and Nazzi and Bertoncini (2009) and Swingley's (2009) mispronunciation detection task were not sufficiently sensitive to reveal the asymmetries shown in some adult studies (e.g. Creel \& Dahan, 2010). To evaluate this possibility a computer-mediated version of this task with children's gaze tracked when presented with visual representations of objects could potentially reveal processing differences between non-initial and initial contrasts.

If the absence was found to be robust across tasks then it could be argued that the importance of word-initial position in adult lexical recognition is an emerging property after 20 to 24 months, as a consequence of computing lexical neighbourhood in an expanding lexicon. That is, when encoding a new word, children would gradually learn to devote more attention to word onsets than to word offsets (segments or syllables), with the initial consonant or syllable of a word being to serve as an efficient sorting element in a Cohort-like model of word recognition (e.g. Marslen-Wilson, 1987). Before that stage the relatively sparse lexical neighbourhood would allow the distance between lexical entries to be measured by information at different positions of the word. It is also possible that word onsets come to be increasingly important over the course of lexical devel- 
opment due to increases in processing speed, and consequently working memory abilities, which are typically observed throughout childhood (see Fry \& Hale, 1996; Marchman \& Fernald, 2008). Therefore, increases in processing speed may lead to reductions in the temporal window of analysis used during speech perception, reducing focus to smaller and smaller chunks of speech until recognition is reliant upon the fast and efficient analysis of word onsets.

Moving to another of our experimental factors, it was found that the stress pattern of our stimuli did not have an absolute effect over the detection of phonemic contrasts. These contrasts were detected more accurately within stressed syllables, no matter whether they were located within trochaic or iambic words. Similarly, stress pattern did not affect the low degree of accuracy for contrasts located within unstressed syllables. Neither our study nor Vihman et al.'s (2004) with 11-month-olds found evidence to support a trochaic bias, such as that found with studies of English-learning infants (Curtin, Mintz \& Christiansen, 2005; Jusczyk et al., 1999) and adults (e.g. Cutler \& Norris, 1988; Cutler \& Butterfield, 1992; Echols et al., 1997). Therefore we could not lend credence to the hypothesis that the predominant word form, represented by the trochaic pattern, facilitates word-level acquisition. This lack of facilitation is similar to findings recently reported for another type of perceptual bias, namely the labial-coronal bias. Labialcoronal (LC) words (e.g. pat) are more frequent than coronal-labial (CL) words (e.g. tap) in most languages (Vallée, Rousset \& Boë, 2001), more frequent in children's productions during their second year (MacNeilage \& Davis, 2000), and preferred in perception by 10 months of age (Gonzalez Gomez \& Nazzi, submitted; Nazzi, Bertoncini \& Bijeljac-Babic, 2009). However, they are not learned any more effectively than CL words in word learning tasks similar to that employed in this study (Nazzi \& Bertoncini, 2009). To draw further conclusions on this subject, younger children would have to be tested, as the 20- to 24-month-old children tested in these studies may have been able to overcome any such bias (ceiling effect).

Although neither the position of the phonemic contrast nor the stress pattern of the stimuli had absolute effects on phonemic discrimination, when these factors were combined it was clear that children were able to access phonetic information more accurately in stressed syllables than in unstressed ones. This suggests that in English supra-segmental information modulates the availability of segmental information in young children (as had been found for known word recognition at 11 months; Vihman et al., 2004; but see Johnson, 2005). Moreover, post-hoc experimentation, using both same/different and transcription tasks, showed that adults had no difficulty in perceiving the phonetic identity of either stressed or unstressed syllables. This indicates that children's difficulty with phonemic contrasts in unstressed syllables is not likely to be due to poor phonetic realization. However, future research will be required to establish whether these difficulties are due to children's inability to process phonetic information in unstressed syllables or to represent that information (which could be perceived, but not used, to build lexical representations).

Finally, analyses of the variation in the phonetic discrimination between individual stimulus pairs highlighted the fact that ambisyllabicity has an important modulating influence upon children's performance. Although the study was not originally designed to address this issue, children seemed to have more problems in discriminating phonetic differences if there was prevalence to ambisyllabicity in the pivotal intervocalic consonant of the stimuli. This effect was found only in trochaic word forms, a pattern which itself increases the tendency to be analysed as ambisyllabic segments over iambic pattern. This effect was such that in Experiment 1, the trochaic items without ambisyllabic pivotal consonants had the highest rates of discrimination success, while performance for the trochaic items with ambisyllabic consonants was at chance. That no such effect was found in paired iambic items suggests that this was not due to the identity of the pivotal consonant.

We propose two possible explanations to explain the effect that ambisyllabicity has over the detection of phonemic contrasts. First, children compute a full representation of every strong syllable, and the specification of this representation is more consistent and accurate if there is no variability caused by ambisyllabic segments. A more specific representation of stressed syllables would help onset detection, when the contrast is at the onset of either the first syllable (Experiment 1) or the second syllable (Experiment 2). Another possibility is that the ambisyllabic effect is due to attention, with the structure of the task leading children to focus on both strong and weak syllable onsets in the search for the discriminative contrast. If one of the segments is ambisyllabic this impedes this attentional mechanism. For either hypothesis one would predict that the effect of ambisyllabicity in trochaic items would be stronger when the to-be-attended contrast is precisely located on the ambisyllabic pivotal consonant. However, our results do not support this prediction. Thus, more research is clearly required to examine the links between stress and ambisyllabicity in early lexical representations.

In summary, our study shows that in an object manipulation word learning situation young Englishlearning children spontaneously focus their attention upon the stressed syllables in new sequences, but do not process unstressed syllables in great detail. This finding holds irrespective of the location of stressed syllables in the sequences, that is in both trochaic and iambic words. This indicates that at the end of a child's second year the processing of the phonetic detail of newly learnt words is not yet fully mature, and, at least in English, is modulated by stress-related properties of the to-be-analysed syllables. More research will be necessary to understand 
the developmental pathway that leads these Englishlearning children from such an asymmetric level of processing between stressed and unstressed syllables to fully mature processing of phonetically specified representations of words in their native language.

\section{Acknowledgements}

We wish to thank two anonymous reviewers and Nuria Sebastián-Gallés for very helpful comments on earlier versions of this paper.

\section{References}

Allen, G.D., \& Hawkins, S. (1980). Phonological rhythm: definition and development. In G.H. Yeni-Komshian, J.F. Kavanagh, \& C.A. Ferguson (Eds.), Child phonology: Vol. 1. Production (pp. 227-256). New York Academic Press.

Anderson, J., \& Jones, C. (1974). Three theses concerning phonological representations. Journal of Linguistics, 10, 1-26.

Bailey, T.M., \& Plunkett, K. (2002). Phonological specificity in early words. Cognitive Development, 17 (2), 1265-1282.

Brown, G. (1977). Listening to spoken English. London: Longman.

Charles-Luce, J., \& Luce, P.A. (1990). Similarity neighbourhoods of words in young children's lexicons. Journal of Child Language, 22 (3), 727-735.

Christophe, A., Nespor, M., Guasti, M.T., \& Van Ooijen, B. (2003). Prosodic structure and syntactic acquisition: the case of the head-direction parameter. Developmental Science, 6 (2), 211-220.

Content, A., Kearns, R.K., \& Frauenfelder, U.H. (2001). Boundaries versus onsets in syllabic segmentation. Journal of Memory and Language, 45, 177-199.

Creel, S.C., \& Dahan, D. (2010). The effect of the temporal structure of spoken words on paired-associate learning. Journal of Experimental Psychology: Learning, Memory, and Cognition, 36 (1), 110-122.

Curtin, S. (2010). Young infants encode lexical stress in newly encountered words. Journal of Experimental Child Psychology, 105 (4), 376-385.

Curtin, S., Mintz, T.H., \& Christiansen, M.H. (2005). Stress changes the representational landscape: evidence from word segmentation. Cognition, 96 (3), 233-262.

Cutler, A., \& Butterfield, S. (1992). Rhythmic cues to speech segmentation: evidence from juncture misperception. Journal of Memory and Language, 31 (2), 218-236.

Cutler, A., \& Carter, D.M. (1987). The predominance of strong initial syllables in the English vocabulary. Computer Speech \& Language, 2 (3-4), 133-142.

Cutler, A., \& Norris, D. (1988). The role of strong syllables in segmentation for lexical access. Journal of Experimental Psychology: Human Perception and Performance, 14, 113-121.

Di Cristo, A. (1998). Intonation in French. In D. Hirst \& A.D. Cristo (Eds.), Intonation systems: A survey of twenty languages (pp. 195-218). Cambridge: Cambridge University Press.

Echols, C., Crowhurst, M.J., \& Childers, J.B. (1997). The perception of rhythmic units in speech by infants and adults. Journal of Memory and Language, 36, 202-225.
Echols, C., \& Newport, E.L. (1992). The role of stress and position in determining first words. Language Acquisition, 2, 189-220.

Eilers, R.E., Gavin, W., \& Wilson, W.R. (1979). Linguistic experience and phonemic perception in infancy: a crosslinguistic study. Child Development, 50, 14-18.

Eimas, P.D., Siqueland, E.R., Jusczyk, P.W., \& Vigorito, J. (1971). Speech perception in infants. Science, 171, 303-306.

Fennell, C.T., \& Werker, J.F. (2003). Early word learners' ability to access phonetic detail in well-known words. Language and Speech, 46, 245-264.

Floccia, C., Nazzi, T., \& Bertoncini, J. (2000). Unfamiliar voice discrimination for short stimuli in newborns. Developmental Science, 3 (3), 333-343.

Fry, A.F., \& Hale, F. (1996). Processing speed, working memory and fluid intelligence. Psychological Science, 7 (4), 237-241.

Gimson, A.C. (1989). An introduction to the pronunciation of English. New York: Edward Arnold.

Gonzalez Gomez, N., \& Nazzi, T. (submitted). Acquisition of non-adjacent phonological regularities in the first year of life: evidence from a perceptual equivalent of the labial-coronal effect.

Hallé, P., \& de Boysson-Bardies, B. (1994). Emergence of an early lexicon: infants' recognition of words. Infant Behavior and Development, 17, 119-129.

Hallé, P., \& de Boysson-Bardies, B. (1996). The format of representation of recognized words in infants' early receptive lexicon. Infant Behavior and Development, 19 (4), 463-481.

Hamilton, A., Plunkett, K., \& Schafer, G. (2000). Infant vocabulary development assessed with a British Communicative Development Inventory: lower scores in the UK than the USA. Journal of Child Language, 27, 689-705.

Havy, M., \& Nazzi, T. (2009). Better processing of consonantal over vocalic information in word learning at 16 months of age. Infancy, 14 (4), 439-456.

Hayes, B. (1995). Metrical stress theory: Principles and case studies. Chicago, IL: University of Chicago Press.

Höhle, B., Bijeljac-Babic, R., Herold, B., Weissenborn, J., \& Nazzi, T. (2009). Language specific prosodic preferences during the first half year of life: evidence from German and French infants. Infant Behavior and Development, 32, 262-274.

Johnson, E.K. (2005). English-learning infants' representations of word forms with iambic stress. Infancy, 7 (1), 99-109.

Johnson, E.K., Jusczyk, P.W., Cutler, A., \& Norris, D. (2003). Lexical viability constraints on speech segmentation by infants. Cognitive Psychology, 46 (1), 65-97.

Jusczyk, P.W., \& Aslin, R.N. (1995). Infants' detection of sound patterns of words in fluent speech. Cognitive Psychology, 29, 1-23.

Jusczyk, P.W., Cutler, A., \& Redanz, N.J. (1993). Infants' preference for the predominant stress patterns of English words. Child Development, 64 (3), 675-687.

Jusczyk, P.W., Houston, D.M., \& Newsome, M. (1999). The beginnings of word segmentation in English-learning infants. Cognitive Psychology, 39, 159-207.

Ladefoged, P. (1993). A course in phonetics. Orlando, FL: Harcourt Brace.

Lahiri, A. (2001). Metrical patterns. In M. Haspelmath (Ed.), Language typology and language universals (pp. 1347-1366). Berlin: Walter de Gruyter. 
Lasky, R.E., Syrdal-Lasky, A., \& Klein, R.E. (1975). VOT discrimination by four to six and a half month old infants from Spanish environments. Journal of Experimental Child Psychology, 20, 215-225.

MacNeilage, P.F., \& Davis, B.L. (2000). The motor core of speech: a comparison of serial organization patterns in infants and languages. Child Development, 71, 153-163.

Mani, N., \& Plunkett, K. (2007). Phonological specificity of vowels and consonants in early lexical representations. Journal of Memory and Language, 57 (2), 252-272.

Mani, N., \& Plunkett, K. (2008). Fourteen-month-olds pay attention to vowels in novel words. Developmental Science, 11, 53-59.

Marchman, V.A., \& Fernald, A. (2008). Speed of word recognition and vocabulary knowledge in infancy predict cognitive and language outcomes in later childhood. Developmental Science, 11 (3), 9-16.

Marslen-Wilson, W.D. (1987). Functional parallelism in spoken word-recognition. Cognition, 25 (1-2), 71-102.

Metsala, J.L., \& Walley, A.C. (1998). Spoken vocabulary growth and the segmental restructuring of lexical representations: precursors to phonemic awareness and early reading ability. In J.L. Metsala \& L.C. Ehri (Eds.), Word recognition in beginning literacy (pp. 89-120). Mahwah, NJ: LEA.

Nazzi, T. (2005). Use of phonetic specificity during the acquisition of new words: differences between consonants and vowels. Cognition, 98, 13-30.

Nazzi, T., \& Bertoncini, J. (2009). Phonetic specificity in early lexical acquisition: new evidence from consonants in coda positions. Language and Speech, 52 (4), 463-480.

Nazzi, T., Bertoncini, J., \& Bijeljac-Babic, R. (2009). A perceptual equivalent of the labial-coronal effect in the first year of life. Journal of the Acoustical Society of America, 126 (3), 1440-1446.

Nazzi, T., Dilley, L.C., Jusczyk, A.M., Stattuck-Hufnagel, S., \& Jusczyk, P.W. (2005). English-learning infants' segmentation of verbs in fluent speech. Language and Speech, 48, 279-298.

Nazzi, T., Floccia, C., Moquet, B., \& Butler, J. (2009). Bias for consonantal over vocalic information in 30-month-olds: crosslinguistic evidence from French and English. Journal of Experimental Child Psychology, 102 (4), 422-537.

Nazzi, T., \& Gopnik, A. (2001). Linguistic and cognitive abilities in infancy: when does language become a tool for categorization? Cognition, 80 (3), B11-B20.

Nazzi, T., Iakimova, G., Bertoncini, J., Frédonie, S., \& Alcantara, C. (2006). Early segmentation of fluent speech by infants aquiring French: emerging evidence for crosslinguistic differences. Journal of Memory and Language, 54, 283-299.

Nazzi, T., Jusczyk, P.W., \& Johnson, E.K. (2000). Language discrimination by English-learning 5-month-olds: effects of rhythm and familiarity. Journal of Memory and Language, 43, $1-19$.

Nazzi, T., \& New, B. (2007). Beyond stop consonants: consonantal specificity in early lexical acquisition. Cognitive Development, 22 (2), 271-279.

Norris, D., McQueen, J.M., Cutler, A., \& Butterfield, S. (1997). The possible-word constraint in the segmentation of continuous speech. Cognitive Psychology, 34 (3), 191-243.
Rost, G.C., \& McMurray, B. (2009). Speaker variability augments phonological processing in early word learning. Developmental Science, 12 (2), 339-349.

Saffran, J.R., \& Estes, K.G. (2006). Mapping sound to meaning: connections between learning about sounds and learning about words. In R. Kail (Ed.), Advances in child development and behavior (Vol. 34, pp. 1-38). New York: Elsevier.

Sebastián-Gallés, N., Dupoux, E., Segui, J., \& Mehler, J. (1992). Contrasting syllabic effects in Catalan and Spanish. Journal of Memory and Language, 31, 18-32.

Stager, C.L., \& Werker, J.F. (1997). Infants listen for more phonetic detail in speech perception than in word-learning tasks. Nature, 388, 381-382.

Streeter, L. (1976). Language perception of two-month-old infants shows effects of both innate mechanisms and experience. Nature, 259, 39-41.

Swingley, D. (2003). Phonetic detail in the developing lexicon. Language and Speech, 46, 265-294.

Swingley, D. (2009). Onsets and codas in 1.5-year-olds' word recognition. Journal of Memory and Language, 60, 252-269.

Swingley, D., \& Aslin, R.N. (2000). Spoken word recognition and lexical representation in very young children. Cognition, 76 (2), 147-166.

Trammel, R.L. (1993). English ambisyllabic consonants and half-closed syllables in language teaching. Language Learning, 43 (2), 311-356.

Trehub, S.E. (1976). The discrimination of foreign speech contrasts by infants and adults. Child Development, 47 (1), 466-472.

Treiman, R., Bowey, J.A., \& Bourassa, D. (2002). Segmentation of spoken words into syllables by English-speaking children as compared to adults. Journal of Experimental Child Psychology, 83, 213-238.

Treiman, R., \& Danis, C. (1988). Syllabification of intervocalic consonants. Journal of Memory and Language, 27, 87-104.

Vallée, N., Rousset, I., \& Boë, L.J. (2001). Des lexiques aux syllabes des langues du monde. Typologies, tendances et organisations structurelles. Linx, 45, 37-50.

Vihman, M.M., DePaolis, R.A., \& Davis, B.L. (1998). Is there a 'trochaic bias' in early word learning? Evidence from infant production in English and French. Child Development, 69 (4), 935-949.

Vihman, M.M., Nakai, S., DePaolis, R.A., \& Hallé, P. (2004). The role of accentual pattern in early lexical representation. Journal of Memory and Language, 50, 336-353.

Walley, A.C. (1993). The role of vocabulary development in children's spoken word recognition and segmentation abilities. Developmental Review, 13 (3), 286-350.

Yoshida, K.A., Fennell, C.T., Swingley, D., \& Werker, J.F. (2009). Fourteen-month-old infants learn similar-sounding words. Developmental Science, 12 (3), 412-418.

Received: 3 November 2009

Accepted: 19 July 2010 